\title{
¡...ESCUCHA, WINKA...! (2006)
}

Pablo Mariman, Sergio Caniuqueo, Rodrigo Levily José Millalen 



\title{
;...ESCUCHA, WINKA...!
}

\author{
Pablo Mariman, Sergio Caniuqueo, Rodrigo Levil y José Millalen
}

\section{INTRODUCCION $^{1}$}

\section{Política y Conocimiento}

En un seminario sobre educación e interculturalidad organizado por el colegio Verbo Divino en Santiago, se invitó a José Bengoa para hablar sobre la historia del pueblo Mapuche. En ese tiempo (3 de enero de 2003) la política del "garrote" acababa de descabezar a una de las organizaciones más activas del movimiento, la coordinadora aranko-malleko, a través de un trabajo de inteligencia policial denominado "operación paciencia" que coordinaba el subsecretario de gobierno Correa Sutil. Luego de terminada la charla un profesor expresó que ahora le quedaba claro por qué los Mapuche hablaban de recuperación, a lo que el expositor señaló que había que precisar ese concepto, pues lo que verdaderamente reivindicaban las comunidades eran las tierras que les había dejado el Estado a través del proceso de radicación indígena (1884-1930). Esta dudosa respuesta de una de las insignias del indigenismo criollo no estaba fundada en el desconocimiento del pasado, sino en una posición de interés -muy en sintonía con el gobierno- que trata de legitimar el paradigma de integración indígena empleado por el Estado, sin involucrar a éste en el origen, desarrollo y reproducción de las desigualdades en que vive la sociedad Mapuche.

Bengoa por ese mismo tiempo, junto a una pléyade de investigadores y académicos chilenos, se encontraba trabajando al interior de una comisión de gobierno que Lagos conformó en el contexto de una política de diálogo con el nombre de Nuevo Trato y Verdad Histórica. El estaba a cargo de la subcomisión de historia. En sus argumentos, para éste y para otros historiadores chilenos, las tierras sobre las cuales el Estado podría contraer una deuda con los mapuche son sólo aquellas que dejó el proceso de radicación a través de la entrega de títulos de merced. Es decir, si los Mapuche en el Ngulumapu (Chile) quedamos con 500 mil hectáreas (el 5\% de los 10 millones de hectáreas que se nos reconocieron en los parlamentos) perdiendo posteriormente $200 \mathrm{mil}(40 \%)$ por la aplicación de las leyes

1. Introducción completa del libro ;...Escucha, winka...! Cuatro ensayos de Historia Nacional Mapuche y un epilogo para el futuro, publicado por editorial LOM. 
indígenas de división de comunidades (1930-1990), entonces ESTA SERÍA LA DEUDA OFICIAL A RECONOCER POR EL ESTADO, con el aval intelectual de quienes prestan su nombre natural e institucional, a veces desinteresadamente. E1 95\% restante es parte del paisaje jurídico que se embolsaron los fundos, el mismo Estado, los colonos (chilenos y extranjeros), y que se nos quiere hacer ver -por acuerdo entre los que saben y los que mandan-, que siempre fue así.

Indagando cómo pueden convencerse de esto, captamos que entre sus argumentos subyace la idea que la radicación se hizo sobre la tierra pareja o aquella que podía ser utilizada económicamente para ganadería o agricultura, por lo que los porcentajes que manejamos de lo que se nos reconoció en propiedad se relativizan (y se entienden las "bondades" del legislador de la época al dejarnos con porcentajes de tierra "reales" para nuestra mantención). Entonces los espacios correspondientes a montañas, pampas, estepas, litorales u otros lugares que no tuvieran poblamiento permanente ni uso periódico, no tenían soberanos o mejor dicho no nos pertenecían. Este argumento "las tierras son de quienes las hacen productivas y no exclusivamente de quienes las ocupan" se parece mucho al que usara en el Puel Mapu el coronel Mancilla en Leubuco en 1869 al responder al lonko Pangetrur ngurru sobre por qué se habían pasado del límite del río cuarto. Estos indigenistas y otros investigadores parten del supuesto que los Mapuche no tuvimos sentido de la soberanía territorial, ni tenemos memoria...pero ahí están las FUENTES, y en muchas de ellas aparecen los lonko, como Mañil wenu a mitad del siglo XIX, recordándoles a las autoridades chilenas de la época que la frontera que había que respetar era el río Biobio, de acuerdo al parlamento de Negrete del año 1803. Pero por lo visto las fuentes son naipes en un juego sucio donde el mazo lo baraja y reparte el mismo Estado.

Miramos con pasmo algunos resultados que surgen de las buenas intenciones de estas comisiones, cuyos fines políticos sólo dan tiempo a los dueños del poder, sea parando una movilización a gran escala o bien para nutrirse de argumentos e información en contra de esos mismos movimientos. Resultó increíble que la subcomisión de historia, a pesar de haberse nutrido de fuentes e investigadores serios y de renombre en la temática indígena ni siquiera haya hecho aparecer al Estado como responsable del empobrecimiento "sostenible" de los Mapuche durante el siglo XX, ni del no reconocimiento de sus derechos como Pueblo. Sabemos que las discusiones en la subcomisión jurídica abordaron temas de derechos tras los paradigmas de la autodeterminación. Sin embargo las recomendaciones sacadas a la luz por el presidente Lagos, solo mencionan la ya vieja cantinela del reconocimiento constitucional y el convenio 169.... Resulta paradójico salir del país y observar cómo en otros países no lejanos y hasta fronterizos con Chile el tema de la autonomía es una realidad en la relación de los pueblos indígenas con sus Estados. No se trata de 
una cuestión de proporcionalidad demográfica, sino de derechos humanos de nivel colectivo. Sin embargo, aquí parece ser una quimera condenable por quienes hasta ahora se amparan en legislaciones fascistas que nos ponen en el banquillo de los acusados tan sólo por recordarles que por más que se sientan modernos la historia los está fosilizando. Estamos aún en la oscuridad, la misma que sentíamos no iba a cambiar cuando gobernaban hasta hace poco los militares golpistas. Sin embargo, $e$ pur si muove, ese tiempo pasó y éste que vivimos está condenado a pasar (esperamos que para bien de todos). Por lo visto los intelectuales e investigadores chilenos deben aprender que las buenas intenciones tan bién son aprovechadas políticamente, es decir, por más que metan sus conocimientos al horno del entendimiento no va a salir humo blanco. Deben saber practicar y creerse el hecho de ser sociedad civil, no correr a la primera invitación a comisionarse ni sentirse comprometidos con los intereses de un Estado que ha actuado oligárquicamente, opinión de consenso en la mayor parte de los historiadores.

\section{WINKAS Y WINKAS}

¡iResentidos!! Seguramente será la expresión que mejor recoja el ánimo de nuestros enemigos e incultos de la historia. Estamos tan habituados a que no se discuta nada para no desarmar lo ya establecido (como las ideas). Mejor será quedarnos en el anonimato y así no hacernos responsables de las repercusiones de lo que aquí salga. Sin embargo, nuestro libro "escucha winka" se llama así para llamar la atención de aquél que pasa de largo haciendo el ademán del desinterés. Se nos podrá criticar que estamos metiendo bajo el término winka a obreros y patrones, momios e izquierdistas, estudiantes y académicos, flaites y cuicos, hombres y mujeres, secundarios y jubilados, todos en un mismo saco, Y ASÍ ES...FELEY MAY... no por maldad, ni por desentendernos de los fenómenos de clases en la sociedad, ni de la territorialidad del fenómeno (los winkas que llegaron con la ocupación del territorio Mapuche, son distintos a los que emigraron y trabajan en una gran urbe, como Santiago). Evidentemente todos los allí nombrados tienen percepciones y actitudes distintas y contrapuestas incluso sobre lo indígena. Sin embargo, ninguno aporta ni ha hecho algo por superar las condiciones de colonialismo que los ponen en una relación de poder respecto a las poblaciones indígenas. Sí, es cierto, reconocen o se refieren al folklore, a lo místico y lo cósmico, a casos puntuales de violación de derechos humanos a comunidades y dirigentes, en fin, a la riqueza que aportamos en materia de multiculturalidad para el país... aunque nuestros sueños de autonomía los asocien a "Estado dentro de otro Estado" y comience con esto la danza de estereotipos que los hace aparecer como un solo cuerpo (...ijmilagro!!...), una sociedad donde el urbano-popular, el clase media y el abc1 sacan a relucir su escudo y bandera ante el Indio. 
Estamos conscientes y reconocemos la existencia de sectores progresistas en la sociedad chilena (congregados, por ejemplo, en los foros alternativos al orden neoliberal mundial), que reivindican otro tipo de ciudadanía y otra reformulación del contrato con el Estado. Por lo mismo entendemos que al no existir mecanismos de participación política verdaderamente democráticos en el país (sólo pensemos en el binominalismo), que les hagan saltarse a la clase política que los (nos) gobierna, al final sus ideas no fluyen, volviéndose-como el resto de la sociedad- en reproductores del estado-nación. Así como los patricios necesitaban de los plebeyos y el yin del yang, visto de manera diáfana desde acá (sea una población, una comunidad, una organización o la cárcel), aparecen todos como un solo muro. Quizás nos podríamos quedar con esta visión y ubicarlos en la posición del enemigo, pero tenemos la certeza que madurará en ellos (ustedes) una posición ni paternal ni mesiánica hacia nosotros, que resquebraje la careta de winka y reformatee el disco duro que les inoculó el criollo, el único y verdadero winka. Cuando no sean considerados tan sólo como masas votantes o consumidoras, sino como sujetos diferenciados de una nación plurinacional, quizás la categoría winka caiga en desuso, como esperamos también se vengan abajo nuestras condenas absolutas a ustedes por el papel que jugó su Estado en nuestra dominación y empobrecimiento. Al menos políticamente nos damos cuenta que pensar el futuro -como lo hace este libro de historia en su epílogo- nos lleva a asumir su presencia y la posibilidad de entendernos profunda y respetuosamente.

\section{AUTONOMISTAS LIBERALES Y CONSERVADORES}

Las generalizaciones como las reducciones en los análisis históricos no pueden escudarse en lecturas políticas del presente. Por lo visto existe mucha ignorancia de la historia entre nuestros dirigentes e intelectuales y, sobre todo, una soberbia ante el fenómeno cultural. En este libro hablamos de líderes pasados y presentes, por lo mismo esperamos no invocar sus nombres en vano. Sin embargo y de acuerdo a los antecedentes que disponemos, muchos de éstos aparecen de manera ambivalente, sea como entreguistas yanakonas o como ilustres patriotas, a veces como péndulo se mueven muy bien entre ambos extremos. La verdad es que esos "próceres" Mapuche, más que parecerse a las figuras de bronce que abundan en las ciudades infectadas de fecas de palomas, son como nosotros, seres incoherentes -hasta inconsecuentes de acuerdo al formato ontológico que tengamos internalizado-, pero capaces de superarse y remendar la historia. Hay que tener cuidado a la hora de juzgar o hacer ver las cosas torcidamente, como cuando se pretende que el análisis histórico no gravite en la política contingente actual, cuestión que como postonazo a veces 
nos llega al hojear las pocas tribunas periodísticas mapuche. No es casualidad que quienes entre nosotros (Mapuche) cuestionan la "tradicionalidad" les acomode y muy bien el traje liberal que en política nos habla de laicismo, democracia, igualdad. Evidentemente son sectores que han hecho su vida no esquivando las bostas del buey en el surco. Sacrificadamente tienen un medidor, sea de luz o agua (sino de gas), que les indica que seguirán conectados si cumplen el contrato social. Los mismos que cuestionan los discursos de las identidades territoriales invocan al gigante urbano, como si existiera una contradicción entre estos procesos, o no fueran estos últimos una de las identidades territoriales que primero se afirmó como tal.

n su otro extremo, los conservadores, o quienes se parapetan en la idea de linajes y purezas, centrando el discurso en lo cultural y en agentes que operan casi en el terreno exclusivo de lo puramente cósmico y místico, como si los grandes lonko no hubieran liderado las batallas de su pueblo, como si las machis no hablaran (y por su intermedio genmapun, genechen) de escasez de tierras y de recuperación. Pero por lo visto algunos de éstos no se incomodan ejecutando proyectos Conadi para celebrar el we tripantu, asignándoles a estas autoridades roles puramente "culturales". Para ellos el pasado siempre será bueno y criticarlo es una deslealtad. El pasado más que mostrarles una sociedad casi anárquica viviendo del mito del buen salvaje (como sucede con algunos liberales), les habla de un pueblo con sólidas estructuras encargadas de reproducir: linajes, valores, cosmovisiones, etc

Ambos extremos -liberales y conservadores- se tocan, como kaykay y trentren. Lo nuevo es que no es una disputa de integración como la protagonizaron Venancio Coñuepán y Antonio Chihuailaf en la década del cincuenta del siglo XX. En la actualidad ambos son parte de la pluralidad del discurso autonomista Mapuche, habiendo entre ellos una amplia gama de posiciones que combinan estos extremos o mantienen su equidistancia de los mismos. Cada uno de éstos debe imperiosamente abandonar su absolutismo, pues ponen en riesgo uno de los elementos vitales de la política de cualquier movimiento que lucha contra sus dominadores: LA UNIDAD. Todos hacen un interesante aporte desde donde ponen el énfasis. Así los autonomistas interesados en la fórmula de gobierno que debiera tener la nueva relación con el Estado nos hablan de parlamentos y regiones autónomas; quienes dimensionan el tema de los recursos naturales llaman la atención sobre el debido control territorial; quienes valoran el peso de lo jurídico enmarcan nuestra lucha en el contexto de los derechos bumanos colectivos y de las instituciones internacionales que lo reglamentan (ONU, OEA); quienes reivindican el papel de la lengua, la cultura y la tradición recrean como referentes de gobernabilidad la propia institucionalidad Mapuche..., en fin, todos persiguen objetivos transversales comunes, aunque sus prácticas y estrategias de lucha los atrincheren ya sea en un diario, en internet, en constantes trawunes, en un partido nacionalista, en la defensa medioambiental, en diálogos inoficiosos, 
en movilizaciones desgastadoras, etc, etc. La gran lección de la historia Mapuche, especialmente al enfrentarse en batallas a sistemas dominantes como el hispanocriollo y el chileno-argentino, fue combinar todas las estrategias de lucha y no ponerse a tiro o pelear en el terreno que domina el enemigo, pero para esto hay que tener una cabeza y un cuerpo cohesionado. Esa quizás sea la paradoja que debamos aprender y de la cual estar muy conscientes. Como se explica en este libro el Estado no fue una construcción histórica de los Mapuche. Esa forma piramidal que adquieren las sociedades tiene sus ventajas en la confrontación, hace marchar ordenadamente a parte de sus ciudadanos al sacrificio creando una logística para ello, mientras que el cerebro (la clase política), el mercado y la sociedad se mantienen fuera de los golpes. Nosotros -ahora en un contexto de dominación- quizás debamos entender que esa forma social tiene su funcionalidad y nos puede prestar alguna ayuda en liberarnos. Eso sí, quedarnos en esa forma es una cuestión a resolver soberanamente el día de mañana.

\section{A QUIÉN NOS DIRIGIMOS}

Escribir este libro significó mezclar la interpretación, la pasión, la rigurosidad y la coyuntura con las pésimas condiciones de existencia en que nos hallábamos, a veces con hambre, otras con frustración por no tener trabajo, pero con muchas ganas de vivir para ver el desenlace. Estamos lejos de producir industrialmente nuestro pensamiento. Por lo mismo es que valoramos las iniciativas y espacios que se abren desde editoriales aliadas que entienden la importancia de hacer circular ideas sin que sean condenadas de antemano. Sabemos que para ellos no es fácil, y que son de los que piensan que mucho de esto tendrá impactos en el futuro cercano, pues se trata de nutrir los intelectos e ir creando una corriente de opinión con fundamentos. Cuestión que no ha estado ni estuvo al momento de discutir una ley indígena o en una comisión oficial de asuntos indígenas.

Este libro se hizo pensando en la gente que ignora nuestro presente, que tampoco tiene idea sobre nuestra gravitación en la historia de Chile y la Argentina, y que menos intuye los impactos que puede ocasionar el día de mañana la modificación del Estado al cambiar no tan sólo su naturaleza oligárquica, sino su monoculturalidad, dejando atrás la figura del estado-nación. Pretendemos que este texto ayude a comprender los motivos profundos de quienes hoy acusados de terrorismo deben pagar con cárcel, clandestinidad o refugio político en el extranjero las condenas que les han impuesto los tribunales chilenos, tan sólo por defender o recuperar aquello que la memoria y unos cuantos papeles indican que les pertenece. Este libro es un homenaje y reconocimiento a la figura de Víctor Ankalaf, Aniceto Norin, 
Pascual Pichun, José Naín, Marcelo Catrillanka, Rafael Pichun, Pascual Pichun, Patricia Troncoso, Juan Marileo, Jaime Marileo, Juan Carlos Huenulao y tantos otros que viven procesos injustos o sufren los allanamientos periódicos, a quienes han vivenciado el maltrato de la fuerza pública y la estigmatización de la sociedad.

Estos contenidos se hicieron pensando en las nuevas generaciones de Mapuche que una vez que se desencanten de la colonización mental que hace el Estado desde la educación, encuentren lo que nosotros no tuvimos a mano en ese momento: memoria organizada y sistematizada que les recuerde a quien se deben y que no los confundan formateando su imaginario con un mapa, un escudo o unas cuantas batallas sin importancia. Este libro está hecho con amor y aprecio a los niños de nuestro país: Aliwen, Katriel, Ilwen, Pilmaiken y muchos más que vendrán, para los cuales deseamos vean iniciada la materialización de la autodeterminación en la autonomía. También va dirigido a los padres de los Juanitos, Rositas, Bayron y Marjorie que en nuestros territorios (ngulumapu) se molestan con la discriminación positiva hacia el Mapuche (becas, hogares), por no llegarles nada a ellos (...el que no llora no mama...brothers). A los descendientes de los Mapuche de los pueblos de indios, a los invisibilizados mestizos bisnietos de los labradores, peones y proletarios del norte del Biobio, a los estudiantes, a los trabajadores, a los profesionales e intelectuales aliados con la causa de la democracia, los derechos humanos, la autonomía y la libertad de los pueblos. ii...Wewain pupeñi, pulamgen ka puwenüi...!!

Santiago, Pikum Mapu, junio de 2006 